5. Mulder EJ, van Bockel JH, Maas J, van den Akker PJ, Hermans J. Morbidity and mortality of reconstructive surgery of noninfected false aneurysm detected long after aortic prosthetic reconstruction. Arch Surg. 1998;133:45-9.

6. Mohammadi S, Bonnet N, Leprince P, Kolsi M, Rama A, Pavie A, et al. Reoperation for false aneurysm of the ascending aorta after its prosthetic replacement: surgical strategy. Ann Thorac Surg. 2005; 79:147-52.

7. Villavicencio MA, Orszulak TA, Sundt TM III, Daly RC, Dearani JA, McGregor CG, et al. Thoracic aorta false aneurysm: what surgical strategy should be recommended? Ann Thorac Surg. 2006;82:81-9.

8. Mesana TG, Caus T, Gaubert J, Collart F, Ayari R, Bartoli J, et al. Late complications after prosthetic replacement of the ascending aorta: what did we learn from routine magnetic resonance imaging followup? Eur J Cardiothorac Surg. 2000;18:313-20.

9. Roth M, Lemke P, Schönburg M, Klövekorn W-P, Bauer EP. Aneurysm formation after patch aortoplasty repair (Vossschulte): reoperation in adults with and without hypothermic circulatory arrest. Ann Thorac Surg. 2002;74:2047-50.
10. McGiffin DC, McGiffin PB, Galbraith AJ, Cross RB. Aortic wall stress profile after repair of coarctation of the aorta: is it related to subsequent true aneurysm formation? J Thorac Cardiovasc Surg. 1992;104:924-31.

11. Thorne SA. Pregnancy in heart disease. Heart. 2004;90:450-6.

12. Abbas AE, Lester SJ, Connolly H. Pregnancy and the cardiovascular system. Int J Cardiol. 2005;98:179-89.

13. Elkayam U, Ostrzega E, Shotan A, Hehra A. Cardiovascular problems in pregnant women with the Marfan syndrome. Ann Intern Med. 1995;123:117-22.

14. Meijboom LJ, Vos FE, Timmermans J, Boers GH, Zwinderman AH, Mulder BJ. Pregnancy and aortic root growth in the Marfan syndrome: a prospective study. Eur Heart J. 2005;26:914-20.

15. Gilkeson RC, Markowitz AH, Ciancibello L. Multisection CT evaluation of the reoperative cardiac surgery patient. Radiographics. 2003 23(suppl):S3-17.

16. Gasparovic H, Rybicki FJ, Millstine J, Unic D, Byrne JG, Yucel K, et al. Three dimensional computed tomographic imaging in planning the surgical approach for redo cardiac surgery after coronary revascularization. Eur J Cardiothorac Surg. 2005;28:244-9.

\title{
Congenital mitral stenosis: A rare presentation and novel approach to management
}

\author{
Rachel Pase Sosland, MD, James L. Vacek, MD, and Michael E. Gorton, MD, Kansas City, Kan
}

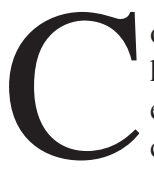

ongenital mitral stenosis is an uncommon congenital heart defect, typically presenting with symptoms in early childhood. ${ }^{1,2}$ This condition remains a surgical challenge, with a trend toward early single-stage complete repair. ${ }^{3}$ We present the case of a 15 -year-old patient given a diagnosis of severe mitral stenosis and pulmonary hypertension. The patient underwent successful complex mitral valve repair with mitral valve ring annuloplasty and neochordae placement and achieved dramatic improvement in symptoms and quality of life.

\section{Clinical Summary}

A 15-year-old boy with a history of asthma was transferred to our hospital with apparent status asthmaticus. He was initially treated for a 5-lobe pneumonia with intravenous antibiotic therapy. He was noted to have a loud holodiastolic murmur, best heard at the left lower sternal border. An echocardiogram was obtained that showed severe mitral stenosis (pressure half-time, $284 \mathrm{~cm} / \mathrm{s}$; mitral valve area, 0.8 $\mathrm{cm}^{2}$ ), significant tricuspid regurgitation, and an estimated systolic right ventricular pressure in excess of $100 \mathrm{~mm} \mathrm{Hg}$. His congestive heart failure responded favorably to diuresis; however, his shortness of breath continued, and he had difficulty attending school.

From the University of Kansas Hospital, Kansas City, Kan.

Address for reprints: James L. Vacek, MD, 3901 Rainbow Blvd, MS 4023

Kansas City, KS 66160 (E-mail: jlvacek@mac.md).

J Thorac Cardiovasc Surg 2007;133:572-3

$0022-5223 / \$ 32.00$

Copyright @ 2007 by The American Association for Thoracic Surgery

doi:10.1016/j.jtcvs.2006.10.025
Follow-up echocardiography indicated a significant decrease in estimated right ventricular and pulmonary artery systolic pressure (60-65 mm Hg). Severe mitral stenosis was again evident, along with significant tricuspid valve regurgitation. His pressure halftime was $238 \mathrm{~ms}$, with a peak gradient of $49 \mathrm{~mm} \mathrm{Hg}$ and an estimated mitral valve area of $0.9 \mathrm{~cm}^{2}$. The posterior leaflet was tethered to the free wall of the left ventricle, and the anterior leaflet was tethered to the tips of the papillary muscles, with essentially no chordae tendineae. The leaflets were normal in appearance. The valve orifice was fixed and severely restrictive.

At the time of the operation, the echocardiographic diagnoses were confirmed. The patient underwent a complex mitral valve repair within weeks of his initial presentation by using the following techniques: (1) transection of trapped chordae tendineae to both the anterior and posterior mitral valve leaflets from both papillary muscles, leaving normal-sized and normal-appearing pliable leaflets without any chordae tendineae; (2) mitral valve ring annuloplasty with a no. 26 Cosgrove annuloplasty ring; and (3) placement of multiple neochordae (5-0 Gore-Tex polytetrafluroethylene sutures; W.L. Gore and Associates, Flagstaff, Ariz), 2 to the anterior leaflet and 3 to the posterior leaflet. Neochordae were used because of the congenital absence of functional chordae.

After the procedure, the patient had a dramatic reduction in tricuspid regurgitation. He was able to resume activities normal for an adolescent boy without shortness of breath. A postoperative echocardiogram was obtained. The echocardiogram demonstrated no residual mitral stenosis and a trivial jet of mitral valve regurgitation. The Doppler estimated right ventricular systolic pressure was $49 \mathrm{~mm} \mathrm{Hg}$. Moderate tricuspid valve regurgitation was noted. Mitral valve flow on Doppler scanning was $178 \mathrm{~cm} / \mathrm{s}$. Our patient continued to be asymptomatic at 1-year follow-up. 


\section{Discussion}

In this case the mitral stenosis resulted from subvalvular fusion and marked foreshortening of the chordae tendineae. This tethered the anterior leaflet to both papillary muscles and the posterior leaflet to the posterior wall of the left ventricle, resulting in a severe conical fixed and restricted valve orifice. This was believed not to be rheumatic because the leaflets were completely normal.

The variety of congenital mitral valve abnormalities ranges from repairable cleft leaflets to restrictive and challenging lesions of isolated mitral stenosis. ${ }^{3}$ Most patients with isolated congenital mitral stenosis have severe symptoms in early childhood. ${ }^{1,2}$ These patients often require early surgical management. When symptoms are mild or even moderate, the operation is delayed in the hope that in the future an adult-sized device can be used. ${ }^{1}$ In patients with congenital mitral valve disease, reconstructive surgery is the primary goal. When necessary, valve replacement can be performed safely with relatively low morbidity and mortality and can provide relief of symptoms for many patients. ${ }^{1,2,4}$ However, mitral valve repair is preferable when feasible to limit implantation of prosthetic material and reduce the need for future reoperation. Also, mitral valve repair reduces the need for long-term anticoagulation and might provide more physiologic correction of the lesion. Our report is notable because of the novel use of neochordae to both leaflets for the repair.

\section{References}

1. Serraf A, Zoghbi J, Belli E, et al. Congenital mitral stenosis with or without associated defects: an evolving surgical strategy. Circulation. 2000;102:166-71.

2. Kadoba K, Jonas RA, Mayer JE, Castaneda AR. Mitral valve replacement in the first year of life. J Thorac Cardiovasc Surg. 1990;100:762-768.

3. Cetin G, Ozkara A, Mert AM, Hatemi AC, Oztunc F, Guven O. Supraannular mitral valve replacement in a child with congenital mitral stenosis. Anadolu Kardiyol Derg. 2004;4:175-7.

4. Günther T, Mazzitelli D, Schreiber C, et al. Mitral-valve replacement in children under 6 years of age. Eur J Cardiothorac Surg. 2000;17:426-430.

\title{
A novel approach to the surgical correction of scimitar syndrome
}

\author{
Tuan T. Lam, MD, Brian L. Reemtsen, MD, Vaughn A. Starnes, MD, and Winfield J. Wells, MD, Los Angeles, Calif
}

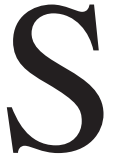

cimitar syndrome is a congenital cardiac malformation in which pulmonary flow from the right lung is partially or totally drained via a venous channel that joins the inferior vena cava (IVC), usually just below the level of the diaphragm. ${ }^{1}$ Options for repair include the creation of a long baffle from the orifice of the scimitar vein within the IVC to the atrial septal defect (ASD) that directs the anomalous pulmonary venous flow to the left atrium, ${ }^{2}$ division with reimplantation of the scimitar vein into the right atrium with an intra-atrial baffle that directs blood flow through an ASD to the left atrium, ${ }^{3}$ partitioning of the IVC into anterior and posterior compartments with a pericardial baffle that channels pulmonary venous blood flow directly into the left atrium, ${ }^{4}$ or direct anastomosis of the divided scimitar vein to the left atrium. ${ }^{5}$ These techniques may be complicated by obstruction of the scimitar vein owing to either baffle thrombosis or kinking of the venous channel. We describe an alternative method for repair of scimitar syndrome using a short polytetrafluoroethylene (Gore-Tex; W. L. Gore \& Associates Inc, Flagstaff, Ariz) interposi-

From the Department of Cardiothoracic Surgery, University of Southern California, Children's Hospital of Los Angeles, Los Angeles, Calif.

Received for publication Oct 6, 2006; accepted for publication Oct 16, 2006.

Address for reprints: Winfield J. Wells, MD, Department of Cardiothoracic Surgery, Children's Hospital of Los Angeles, 4650 Sunset Blvd, Mailbox 66, Los Angeles, CA 90054 (E-mail: wwells@chla.usc.edu).

J Thorac Cardiovasc Surg 2007;133:573-4

$0022-5223 / \$ 32.00$

Copyright () 2007 by The American Association for Thoracic Surgery

doi:10.1016/j.jtcvs.2006.10.021 tion tube graft to ensure freedom from tension or kinking when directly connecting the scimitar vein to the left atrium.

\section{Clinical Summary}

Two patients aged 4 and 14 years have undergone repair for scimitar syndrome with a pulmonary venous extension technique. Both patients had the entire venous return from the right lung via the scimitar vein with a relatively short length of vein from the hilum of the lung to the junction with the IVC. Both patients had a secundum ASD. Preoperative echocardiogram showed right atrial and ventricular dilation. Cardiac catheterization demonstrated the anomalous pulmonary venous return from the right lung associated with an ASD. The pulmonary/systemic flow ratio was 2.6:1 (4-year-old) and 1.4:1 (14-year-old).

Cardiopulmonary bypass with bicaval cannulation was established through a median sternotomy. The patients were cooled before aortic crossclamping and administration of cold blood cardioplegic solution. The scimitar vein was isolated from its point of emergence from the pulmonary parenchyma to its junction with the IVC near the reflection of the diaphragm. Despite dividing the scimitar vein flush with the IVC, there was concern that a direct anastomosis to the left atrium would create acute angulation and kinking. Therefore, a short polytetrafluoroethylene interposition graft (12-mm in the 4-year-old and 16-mm in the 14-year-old) was sewn end to end to the divided scimitar vein; then, through a right atriotomy and via the ASD, the rightward superior lateral aspect of the left atrium was probed and an atriotomy was made. The polytetrafluoroethylene interposition graft was cut to appropriate length and anastomosed end to side to the left atriotomy (Figure 1). The ASD was closed with an autologous pericardial patch. After repair, an 